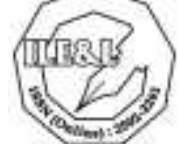

Journal Indonesian Language Education and Literature Vol.1, No. 2, 2016

http://www.syekhnurjati.ac.id/jurnal/index.php/jeill/

\title{
PENGEMBANGAN MODEL SINEKTIK PADA PEMBELAJARAN MENULIS PUISI BERKONTEKS MULTIKULTURAL DALAM PEMBENTUKAN KARAKTER SISWA SMA
}

\author{
Sutikno \\ SMA Negeri Brebes \\ sutikno@gmail.com
}

\begin{abstract}
Abstrak
Pembelajaran menulis puisi masih bersifat monokultural artinya tidak memperhatikan keberagaman yang ada selama ini. Hal ini guru kurang menguasai materi pembelajaxan menulis puisi, padahal pembelaiaran menulis puisi perlu mengangkat keberagaman budaya dilingkungan siswa. Penelitian ini difokuskan pada model sinektik pada pembelajaran menulis puisi berkonteks multikultural. Penelitian ini secara khusus bertujuan mengidentifikasi kebutuhan pengembangan sinektik, memaparkan karakteristik, dan menyusun model sinektik pembelajaran menulis puisi multikultural. Penelitian ini dilakukan dengan desain penelitian dan pengembangan model sinektik pembelajaran menulis puisi multikultural. Teknik analisis data yang digunakan adalah deskriptif kualitatif. Hasil tes awal dan tes akhir, ketuntasan akhir lebih besar dari tes awal. Tes awal yang tuntas $57,14 \%$ dan tes akhir yang tuntas $100 \%$ jadi ada peningkatan $42,86 \%$. Berdasarkan temuan tersebut, dapat dinyatakan bahwa model sinektik dapat meningkatkan pembelajaran menulis puisi multikultural dan memlliki dampak positif dalam pembentukan lnarakter siswa.
\end{abstract}

\section{Kata kunci: model sinektik, pembelajaran menulis puisi, karakter}

Learning to write poetry is still a monocultural means not pay attention to the diversity that exist for this. Teachers did not master the learning material to write poetry, but learning to write poetry to lift the cultural diversity in the student environment. This study focused on the model sinektik on multicultural contextual learning to write poetry. This study is specifically aimed at identifying the development needs sinektik, explained the characteristics and create a model for learning to write poetry sinektik multicultural. This research was conducted by the research design and development models sinektik multicultural learning writing poetry. Data analysis technique used is descriptive qualitative. The results of the initial test and final test, the thoroughness of the larger end of the initial tests. Initial tests were completed $57.14 \%$ and final tests are completed $100 \%$ so there is an increase of $42.86 \%$. Based on these findings, it can be stated that the model can improve learning sinektik writing poetry memlliki multicultural and positive impact in shaping the character of students.

\section{Kata kunci: sinectic model, write poetry learning, character}

\section{A. Pendahuluan}

Pembelajaran menulis puisi sebagian besar dikelola dengan pendekatan konvensional. Dalam penerapannya, sebagian besar kegiatan masih didominasi oleh guru. Aktivitas belajar agak terbatas pada 'mengingat informasi, mengungkapkan 


\section{Journal Indonesian Language Education and Literature Vol.1, No. 2, 2016}

http://www.syekhnurjati.ac.id/jurnal/index.php/jeill/

kembali apa yang telah dikuasainya, dan bertanya kepada guru materi yang belum dipahami (Sudjana 1991:12). Dalam proses pembelaiaran, masih tampak adanya kecenderungan meminimalkan peran dan keterlibatan siswa. Dominasi guru dalam proses pembelajaran menyebabkan siswa lebih banyak berpeian dan terlibat secara pasif, siswa banyak berperan dan terlibat secara pasif, siswa lebih banyak menunggu sajian dari guru daripada mencari dan menemukan sendiri pengetahuan, keterampilan, serta sikap yang mereka butuhkan.

Pembelajaran menulis puisi yang berkonteks multikultural perlu dikembangkan agar siswa memiliki kesadaran yang tinggi dalam menentukan pilihanpilihan yang paling tepat sebagai tuntunan hidup dimasa depan dengan berbagai alat komunikasinya. Salah satunya dengan mengintegrasikan pada mata pelajaran bahasa Indonesia. Dengan demikian, pembelajamn -bahasa Indonesia merupakan media yang dapat menjembatani pendidilcan multikultural melalui keterampilan menulis kreatif.

Salah satu usaha yang dilakukan guru untuk mencapai keberhasilan dalam proses belajar-mengajar adalah pemilihan metode yang tepat. Ketepatan guru dalam memilih metode pembelajaran atau memilih model akan berpengaruh terhadap keberhasilan belajar siswa. Sagala (2005:174) menyatakan bahwa pengajar harus dapat menggunakan model-model dan pendekatan mengajar yang dapat menjamin pembelajaran berhasil sesuai yang direncanakan. Metode mengajar dapat berfungsi optimal, jika diselaraskan dengan materi pelajaran, siswa, dan tujuan pengajaran serta keterampilan menggunakannya.

Hadirnya model pembelajaran hendaknya mengacu pola pikir di atas. Masalahnya model manakah yang tepat agar pembelajaran dapat mencapai mjuan yang diinginkan. Keterampilan memilih itu menjadi sangat penting karena tidak ada satu model yang dapat diterapkan untuk berbagai kegiatan pembelajaran dalam berbagai situasi dan kondisi. Hal ini dipertegas oleh Dahlan (1990:19) sesungguhnya tidak satu model mengajarpun yang paling cocok untuk semua situasi, dan sebaliknya tidak satu situasi mengajarpun yang paling cocok dihampiri oleh semua metode mengajar. Joyce et al (2009:27) menyatakan tentu saja yang lebih penting lagi adalah guru seyogianya memahami dan menguasai macam-macam modelmengajar, karena model mengajar merupakan pola yang dapat digunakan untuk menentukan proses belajar-mengajar, memncang mated pengajaran, dan memandu pengajaran di kelas. 
Suatu pendekatan baru yang menarik dalam mengembangkan kreativitas telah dirancang oleh Gordon dengan nama sinektik. Model sinektik ini merupakan strategi pengajaran yang" baik sekali untuk mengembangkan kemampuan lcreatif dalam menulis (Joyce et al 20091182).

Pembelajaran model sinektik berorientasi untuk meningkatkan kemampuan pemecahan masalah, ekspresi kratif empati, dan wawasan dalam hubungan sosial, sehingga kreativitas siswa akan muncul beragam terutama dalam menulis puisi. Oleh karena itu, peran guru dalam proses pembelajaran diharapkan mampu menumbuhkan rasa menghormati, menghargai, dan toleransi antarteman.

Berdasarkan latar belakang masalah itu, rumusan masalah penelitian ini (1) bagaimanakah kebutuhan pengembangan model sinektik pada pembelqaran menulis puisi berkonteks multikultural dalam pembentukan karakter siswa SMA?,( 2) bagaimanakah karakteristik model sinektik pada pembelajaran menulis puisi berkonteks multikultural yang sesuai di Sekolah Menengah Atas?, ( 3) bagaimanakah model sinektik pada pembelajaran menulis puisi berkonteks multikultuxal dalam pembentukan karakter siswa SMA?

\section{Model Pembelajaran}

Model pembelajaran adalah kerangka konseptual yang melukiskan prosedur yang sistematis dalam mengorganisasikan pengalaman belajar untuk mencapai tujuan belajar teflentu, dan berfungsi sebagai pedoman lgagi para perancang pembelajaran dan para pengajar dalam merencakan aktivitas belajar mengajar.

Arends (1997:7) menyatakan "the terms teaching model refers to a particular approach to instruction that includes its goal, syntax, environmen, and management system”. Istilah model pengajamn mengarah pada suatu pendekatan pembelajaran tertentu termasuk tujuannya, sintaksnya, lingkungannya, dan sistem pengelolaannya.

Istilah model pembelajaran mempunyai makna lelwih luas daripada sttategi, metode atau prosedur. Model pengajaran mempunyai empat ciri khusus, yakni (1) rasional teoretik logis yang disusun oleh para pencipta atau pengembangannya, (2) tujuan pembelajaran apa yang akan dicapai, (3) tingkah laku pengajar yang diperlukan agar metode tersebut dapat dilaksanakan dengan berhasil, (4) lingkungan 
belajar yang diperlukan agar tujuan pembclajaxan itu dapat tercapai (Kardi, dan Nur 2000:9).

Model pembelajaran sinektik bertujuan mengembangkan kreativitas siswa melalui aktifitas metaforik (analogi langsung dan analogi personal) diharapkan mampu mendorong siswa terlibat aktif dalam, tindakan kreatif. Joyce et al (2000: 135) berpendapat sebagai berikut.

Semua model mengajar mengandung unsur model berikut: (a) orientasi model, (b) urutan kegiatan (syntax), (c) sistem sosial (social system), (d) prinsip reaksi (principle of reaction), (e) sistem penunjang (support system), dan (f) dampak instruksional dan penyerta (instructional and nurturant efiizct). Ada dua stmtegi dari model pembelajaran sinektik, yaitu strategi pembelajaran untuk menciptakan sesuatu yang baru (creating something new) dan strategi pembelajaran untuk melazimkan terhadap sesuatu yang masih asing (making the strange familiar). Kedua strategi dari model pembelajaran sinektik dapat dilihat pada tabel berikut.

Tabel 2 Strategi Sinektik I: Menciptakan Sesuatu yang Baru

\begin{tabular}{|c|l|}
\hline \multicolumn{1}{|c|}{$\begin{array}{c}\text { Tahap Pertama: } \\
\text { Mendeskripsikan situasi saat ini }\end{array}$} & \multicolumn{1}{c|}{$\begin{array}{c}\text { Tahap Kedua: } \\
\text { Analogi langsung }\end{array}$} \\
\hline $\begin{array}{l}\text { Guru meminta siswa mendeskripsikan } \\
\text { situasi/topik seperri yang mereka lihat } \\
\text { saat ini }\end{array}$ & $\begin{array}{l}\text { Siswa mengusulkan analogi-analogi } \\
\text { langsung, memilikinya, dan } \\
\text { mengeksplorasi (mendeskripsikan)nya } \\
\text { lebih jauh }\end{array}$ \\
\hline $\begin{array}{c}\text { Anahap Ketiga } \\
\text { Thersonal }\end{array}$ & \multicolumn{1}{c|}{$\begin{array}{c}\text { Tahap Keempat } \\
\text { Konflik Padat }\end{array}$} \\
\hline $\begin{array}{c}\text { Siswa "menjadi" analogi yang telah } \\
\text { mereka pilih dalam tahap kedua tadi }\end{array}$ & $\begin{array}{l}\text { Siswa mengambil deskripsi-deskripsi dari } \\
\text { tahap kedua dan ketiga mengusulkan } \\
\text { beberapa analogi konflik padat, dan } \\
\text { memilih salah satunya. }\end{array}$ \\
\hline $\begin{array}{l}\text { Tahap Keenam } \\
\text { langung yang lain, yang didasarkan pada } \\
\text { analogi konflik padat }\end{array}$ & $\begin{array}{l}\text { Memeriksa Kembali Tugas Awal } \\
\text { tugas/masalah awal dan menggunakan } \\
\text { analogi terakhir dan atau seluruh } \\
\text { pengalaman sintektik }\end{array}$ \\
\hline
\end{tabular}


Journal Indonesian Language Education and Literature Vol.1, No. 2, 2016

http://www.syekhnurjati.ac.id/jurnal/index.php/jeill/

Tabel 3 Stratcgi Sinektik H: Melazimkan Scsuatu yang Asing

\begin{tabular}{|c|c|}
\hline $\begin{array}{l}\text { Tahap Pertama } \\
\text { Input Substantif }\end{array}$ & $\begin{array}{l}\text { Guru menyediakan informasi tentang } \\
\text { topik baru }\end{array}$ \\
\hline $\begin{array}{l}\text { Tahap Kedua } \\
\text { Analogi langsung }\end{array}$ & $\begin{array}{l}\text { Guru mengusulkan analogi langsung dan } \\
\text { memmta siswa mendeskripsikannya }\end{array}$ \\
\hline $\begin{array}{l}\text { Tahap Kefiga } \\
\text { Analogi personal }\end{array}$ & $\begin{array}{l}\text { Guru meminta siswa "menjdi" analogi } \\
\text { langsung }\end{array}$ \\
\hline $\begin{array}{l}\text { Tahap Keempat } \\
\text { Membandingkan analogi-analogi }\end{array}$ & $\begin{array}{l}\text { Siswa mengidentifikasi dan menjelaskan } \\
\text { poin-poin kesamaanr antara materi baru } \\
\text { dengan analogi langsung }\end{array}$ \\
\hline $\begin{array}{l}\text { Tahap Kelima } \\
\text { Menjelaskan perbedaan-perbedaan }\end{array}$ & $\begin{array}{l}\text { Siswa menjelaskan di mana saja analogl- } \\
\text { analog:yang tidak sesuai }\end{array}$ \\
\hline $\begin{array}{l}\text { Tahap Keenam } \\
\text { Eksplorasi }\end{array}$ & Siswa mengeksplorasi kembali topik asli \\
\hline $\begin{array}{l}\text { Tahap Ketujuh } \\
\text { Membuat analogi baru }\end{array}$ & $\begin{array}{l}\text { Siswa mcnyiapkan analogi langsung dan } \\
\text { mengeksplorasi persamaan-persamaan } \\
\text { pcrbedaan-perbedaan }\end{array}$ \\
\hline
\end{tabular}

\section{Menulis Puisi}

Menulis sebagai proses kegiatan pikiran manusia yang hendak mengemukakan kandungan jiwanya kepada orang lain atau kepada diri sendiri dalam bentuk tulisan (Widyamartaya 1991:9). Dalam ha] ini terkandung maksud bahwa menulis suatu proses dan aktivitas yang melahirkan gagasan, pikiran, dan perasaan kcpada orang lain ataupun pada diri scndiri mfilalui media bahasa berupa tulisan. Sedangkan menulis puisi adalah menuangllgan gagasan, pikiran, dan perasaan berupa tulisan yang terikat oleh irama, mantra, rima, serta penyusunan larik dan baris yang indah.

Dalam kamus Istilah Sastra (Sudjiman 1986:61) puisi diartikan sebagai ragam sastra yang bahasanya terikat oleh irama, mant1a,rima sena penyusunan larik, dan baris. Menurut Waluyo (2005:45) puisi adalah karya sastra dengan bahasa yang dipadatkan, dipersingkat, dan diberi irama dengan bnmyi yang padu dan pemilihan kata-kata yang kias atau imajinatif.

Dalam puisi terdapat 3 bentuk permukaan yang berupa larik, bait, dan pertalian makna larik dan bait. Kemudian penyair berusaha mengkonkritkan pengertian dan konsep-konsep abstrak dengan menggunakan pengimajian, pengiasan, dan perlambangan. Dalam mengungkapkan pengalaman jiwanya penyair bertitik tolak pada atmosfir yang dijelmakan oleh lingkungan fisik, dan psikologis dalam puisi. Dalam memilih kata-kata, diadakan perulangan bunyi yang mengakibatkan 
adanya kemerduan atau eufonit Jalinan kata- kata harus memadukan kemanisan bunyi dalam makna. Sementara menurut Teeuw (1980: 112).

Tujuan pengajaran puisi adalah tertampang dalam rumusan sebagai berikut:

a) Untuk membina dan mengembangkan kearifan menangkap berbagai isyarat kehidupan dengan menunjang keterampilan berbahasa, meningkatkan pengetahuan budaya, mengembangkan rasa, karsa, dan pembentukan watak manusia.

b) Untuk memberikan pandangan komprehensif tentang cipta budaya nasional, membina anak didik memiliki rasa bangga, keyakinan? mandiri dan rasa memiliki.

Pembelajaran menulis puisi dapat teljadi dengan efektif jika guru dapat menerapkan strategi-strategi pembelajaran yang dapat memberikan peluang kepada siswa untuk lebih aktif, kreatif, dan inovatif. Stratagi tersebut diharapkan dapat membuat siswa memiliki keyakinan bahwa dirinya mampu belajar yang dapat memanfaatkan potensi siswa seluas-luasnya. Ada enam langkah melakukan strategi pembelajaran menulis puisi; antara lain (1) pemilihan objek yang diingini atau disenangi, (2) imajinasikan objek tersebut, (3) kreasikan imajinasimu daengan katakata, (4) ringkas dan kembangkan kata menjadi larik, (5) padukan dan olah larik-larik mcnjadi bait-bait puisi, dan (6) publikasikan puisimu.

Sementara menurut Komaidi (2007: 207) langkah-langkah dalam menulis puisi sebagai berikut. (1) Sebelum menulis puisi, pahami apa itu puisi. Kita dapat mencoba sebanyak mungkin membaca puisi-puisi yang ada di buku, majalah, atau media massa. Setelah banyak membaca puisi tentu sedikit atau banyak akan tahun apa itu puisi dan bagaimana membuatnya, (2) mencari inspirasi dengan berkelilingkeliling kc alam lingkungan sekitar karena hal itu akan memperluas pengalaman estetik kita untuk dituangkan kc dalam puisi, (3) cobalah catatan atau buku kecil kemana kita pergi. Hal ini untuk menuliskan sctiap ide atau inspirasi berharga yang tcrlintas di pikiran kita agar tidak cepat hilang dan terlewatkan, (4) tulis apa yang ada dalam pikimn, perasaan kita, kegelisahan kita kc dalam bentuk kata-kata dalam puisi dengan bebas tanpa beban, (5) baca dan perbaiki puisi yang sudah dibuat. Setelah selesai mcnulis puisi, coba endapkan scbentar beberapa jam atau beberapa hari kemudian. Sctelah itu baca lagi_ puisi yang sudah dibuat, mungkin kita merasakan sesuatu yang berbeda dan muncul perspektif baru dalam pikiran, (6) setelah selesai lnenulis puisi coba uji puisi yang dibuat untuk dikirimkan kc media massa ataupun 
minta kritik, saran dari orang lain sehingga puisi yang telah dibuat menjadi semakin menarik dan mempunyai nilai estetika tinggi.

\section{Pendidikan Multikultural}

Multikultural yang berakar dari dua kata yaitu multigfberarti banyak dan kultur berarti budaya atau peradaban.Da|am pendidikan Multikultural selalu muncul kata kunci Kultural, pluralitas, dan pendidikan. Pemahaman terhadap pluralitas mencakup segala perbedaan dan keragaman, -1 sedangkan Kultur itu sendiri tidak dapat lepas dari empat terma penting yaitu aliran (agama), ras (etnis), suku dan budaya. Dalam pendidikan multikultural beralti pengakuan atas empat terma penting tersebut untuk memprogramkan berlangsungnya pendidikan multikultural. Pengakuan keempat terma penting tersebut menjadi ciri khas pendidikan multikultural. Maslikha (2007:46) berpendabat sebagai berikut.

Pendidikan multikultural harus dapat memahami keberadaan masyarakat plural yang memiliki grup think yang membutuhkan ikatan-ikatan keadaban (the bound of civility). The bound of civililfy berupa pergaulan antarkultur yang diikat dengan suatu civility (keadaban) ikatan ini dibangun dari nilai-nilai universal. Dengan demikian multikultural berarti keragaman kebudayaan, aneka kesopanan,atau banyak pemeliharaan. Istilah multikulturisme umumnya digunakan untuk menjelaskan suatu situasi heteroginitas budaya atau menunjuk pada eksistensi pluralitas etnik dari berbagai kelompok budaya dalam masyarakat (Sundrijo 2008).

\section{Pendidikan Karakter}

Pendidikan berkarakter berkaitan terutama dengan bagaimana seseorang individu menghayati kebebasannya dalam relasi mercka dengan oiang lain sebagai individu, maupun dengan orang lain sebagai individu yang ada di dalam sebuah struktur yang memiliki kekuasaan. Oleh karena itu, pendidikan karakter tidak sematamata bersifat individual, melainkan juga memiliki dimensi sosial struktur, meskipun pada gilirannya yang menjadi kriteria penentunya adalah nilai-nilai kebebasan individual yang sifatnya personal (Koesoema 2007: 194).

Pendidikan karakter mempersyaratkan adanya pendidikan moral dan pendidikan nilai. Pcndidikan moral menjadi agenda utama pendidikan karakter sebab pada gilirannya seorang yang berkarakter adalah seorang individu yang mampu mcngambil keputusan dan bertindak bebas dalam kerangka kehidupan pribadi 
maupun komunitas yang semakin mengukuhkan keberadaan dirinya sebagai manusia yang bermoral. Oleh karena ruang lingkupnya yang lebih luas, bukan semata-mata berkaitan dengan tata nilai moral, melainkan berkaitan dengan tata nilai dalam masyarakat, pendidikan karakter mengandaikan adanya pendidikan nilai agar individu yang ada dalam masyamkat 'itu dapat berelasi dengan baik dan dengan demikian membantu individu lain dalam menghayati kebebasamya. Dalam masyarakat yang plural dan multikultural, menghormati perbedaan menjadi nilai yang sangat esensial jika masyarakat ingin' hidup berdampingan secara damai. Menghargai perbedaan adalah sebuah nilai yang secara moral bersifat netral.

\section{B. Metode Penelitian}

Penelitian ini dilakukan di dua SMA wilayah utara Kabupaten Brebes Jawa Tengah yaitu SMA Negeri 1 Wanasari, dan SMA Negeri 3 Brebes, dengan sumber data penelitian adalah siswa. Adapun sumber data lain adalah guru dari 4 SMA di Kabupaten Brebes (SMA Negeri 1 Brebes, SMA Negeri 3 Brebes, SMA Negeri Bulakamba, dan SMA PGRI Brebes). Subjek penelitian ini adalah pengembangan model sinektik pada pembelajaran menulis puisi berkonteks multikultural dalam pembentukan karakter siswa SMA.

Pada tahap penelitian dlhasilkan dan dideskripsi analisis kebutuhan guru, kebutuhan siswa yang berpotensi dalam pengembangan model sinektik. Pada tahap pengembangan dihasilkan (1) karakteristik model pembelajaran yang dikembangkan, (2) draf awal desain model, (3) draf hasil perbaikan sesuai rekomendasi ahli, (4) draf final hasil penyempumaan, dan (5) evaluasi berdasarkan refleksi penerapan model pada skala terbatas.

\section{Hasil dan Pembahasan}

\section{Kebutuhan Guru}

Berdasarkan analisis kebutuhan guru dalam pengembangan model sinektik pada pembelajaran menulis puisi berkonteks multikultural dalam pembentukan karakter siswa, diperoleh deskripsi (I) aspek multikultural, (2) perencanaan pembelajaran, (3) pola interaksi dalam pembelajaran, (4) strategi pembelajaran, dan (5) kendala yang dihadapi dalam pembelajaran menulis puisi. 


\section{Kebutuhan Siswa}

Berdasarkan analisis kebutuhan siswa pada pengembangan model sinektik dalam pembelajaran menulis puisi berkonteks multikultural dalam pembentukan kamter siswa diperoleh deskripsi (1) aspek multikultural, (2) pola interaksi dalam pembelajaran, (3) kendala yang dihadapi dalam pembelajaran menulis puisi, (4) nilainilai multikultural.

\section{Karakteristik Model Pembelajaran Sinektik}

Beberapa prinsip yang mendasari pelaksanaan model sinekik pada pembelajaran menulis puisi berkonteks multikultural sebagai berikut. (1) pembelajaran perlu dikaitkan dengan berbagai masalah sosial budaya yang ada di sekitar berbagai masalah sosial budaya yang ada di sekitar lingkungan siswa, (2) gum memiliki wawasan tentang multikultural dalam pembelajaran menulis puisi, (3) interaksi antarsiswa dalam pembelajaran menulis puisi multikultural dilakukan dalam presentasi, (4) pembelajaran menulis puisi diawali dengan ilustrasi tentang multikultural, (5) pembolajaran memberi kesempatan kepada siswa untuk menilai produk puisi teman, (6) kriteria penilaian puisi meliputi aspek budaya, agama, bahasa, sosial, (7) pembelajaran memberikan kesempatan kepada siswa untuk bekelja sama dalam membangun pemahaman dan keterampilan melalui intelaksi dengan lingkungannya, (8) penanaman nilai-nilai moral dalam rangka membangun etika (karakter) siswa, (9) pemberian penghargaan kepada siswa, dan akhir pembelajaran dengan refieksi dan pcmberian tugas siswa.

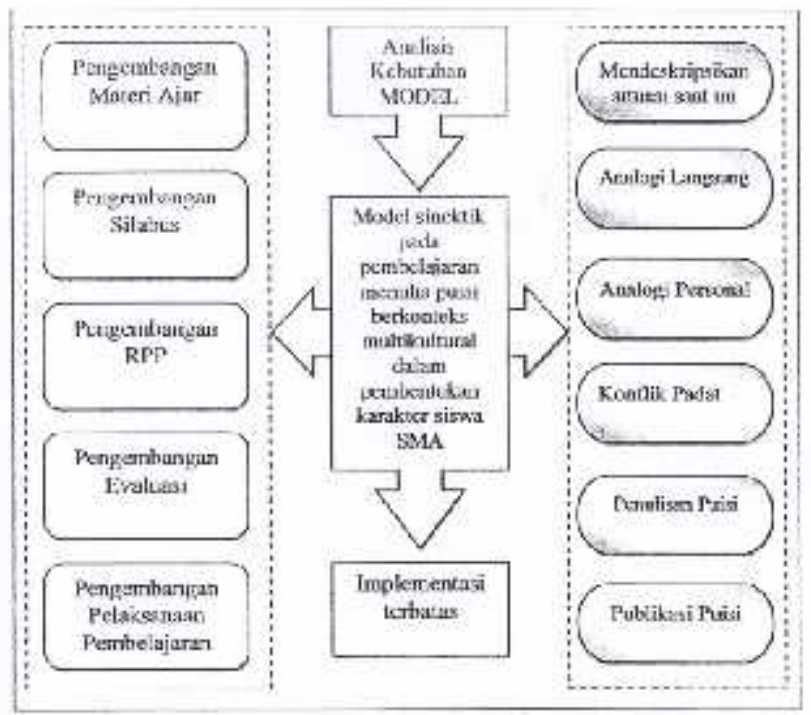


Pengembangan materi ajar menulis puisi ini bertujuan agar siswa mampu memecahkan masalah-masalah sosial yang berada di "Rlingkungan siswa dan menanamkan nilai-nilai multikultural seperti kejujuran, kebersamaan, tanggung jawab, setia kawan, tolong menolong. Pengenalan terhadap masalah-masalah sosial dalam konteks multikultural ini memberikan manfaat bagi siswa untuk dapat memahami Han menghargai perbedaan yang ada. Dengan demikian, siswa dapat lebih arif dalam menghadapi perbedaan-perbedlaan yang begitu kompleks, baik perbcdaan agama, perbedaan gender, perbedaan status sosial, perbedaan bahasa, perbedaan kemampuan, ataupun perbedaan budaya yang ada di lingkungan sekolah, keluarga, atau masyarakat yang pada akhirnya akan membentuk karakter positif pada diri siswa.

\section{Contoh Puisi Multikultural (Bahasa)}

\section{SENYUM MENTARI}

Di kala sang surya menyapa alam

Pagipun menyambut seyum cerah sang surya

Begitupun para petani yang menuju ke sawah

Saling bertegur sapa

Mangga....

Punten....

Selamet pagi

Sugeng enjing....

Horas bah.....

Begitu rutinitas kehidupan di desaku

Yang beraneka suku dan ramah

Seramah mentari pagi menyapa dunia

Kicau burung dan kokok ayampun

Bersahut-sahutan

Menambah semarak suasana

(Magna) 


\section{Pedoman pensekoran menulis puisi}

\begin{tabular}{|c|c|c|}
\hline No. & Kegiatan & Skor \\
\hline 1. & $\begin{array}{l}\text { Siswa menuliskan puisi berdasarkan konteks multikultural } \\
\text { dengan pilihan kata yang tepat }\end{array}$ & 3 \\
\hline 2. & $\begin{array}{l}\text { Siswa menuiiskan puisi berdasarkan konteksfimultikultural } \\
\text { dengan pjlihan kata yang kumng tepat }\end{array}$ & 2 \\
\hline 3. & $\begin{array}{l}\text { Siswa mcnuliskan puisi bcrdasarkan kontcks multikultural } \\
\text { dengan pilihan kata yang tidak tepat }\end{array}$ & 1 \\
\hline 1. & $\begin{array}{l}\text { Puisi yang dibuat rnenggunakan banyak bahasa figurative yang } \\
\text { tepat }\end{array}$ & 3 \\
\hline 2. & $\begin{array}{l}\text { Puisi yang dibuat menggunakan banyak bahasa figurative yang } \\
\text { kurang tepat }\end{array}$ & 2 \\
\hline 3. & $\begin{array}{l}\text { Puisi yang dibuat menggunakan banyak bahasa pigurative yang } \\
\text { tidak tepat }\end{array}$ & 1 \\
\hline 1. & $\begin{array}{l}\text { Siswa menuliskan puisi berdasarkan konteks multikultural } \\
\text { dengan pola persajakan yang tepat }\end{array}$ & 3 \\
\hline 2. & $\begin{array}{l}\text { Siswa menuliskan puisi bcrdasarkan konteks multikultural } \\
\text { dengan pola persajakan yang kurang tepat }\end{array}$ & 2 \\
\hline 3. & $\begin{array}{l}\text { Siswa menuliskan puisi berdasarkan konteks multikultural } \\
\text { dengan pola persajakan yang tidak tepat }\end{array}$ & 1 \\
\hline
\end{tabular}

Skor maksimal 9

Penghitungan nilai skala $0-100$ sebagai berikut

Nilai akhir $=\frac{\mathrm{p}}{\mathrm{s} \quad \mathrm{m}}(\mathrm{s}) \mathrm{x}$ skor ideal (100)

\section{Penutup}

Produk penelitian pengembangan berupa model sinektik oada pembelajaran menulis puisi berkonteks multikultural disusun dan dikembangkan peneliti berdasarkan kebutuhan siswa dan kebutuhan guru (deskripsi aspek multikultural, perencanaan pembelajaramstrategi pembelajaran, dan kendala yang dihadapi dalam pembelajaran menulis puisi), serta penilaian uji validasi dari ahli/pakar.

Dengan demikian, hasil penilaian ahli/pakar berkaitan. model sinektik pada pembelajaran menulis puisi berkonteks multikultural dinyatakan layak dan memadai 
untuk dilaksanakan para guru dalam pembelajaran menulis puisi berkonteks multikultural siswa SMA kelas X.

Produk pengembangan yang dihasilkan berupa model sinektik pada pembelajaran menulis puisi berkonteks multikultural, yang berupa karakteristik model pengembangan, perangkat pembelajalan berisi kompetensi dan kompetensi dasar, silabus, RPP, pedoman peniaian, dan txanskripsi. Model ini mempunyai langkah-langkah dengan mengembangkan model sinektik yaitu Mendeskripsikan situasi saat ini, analogi langsung, analogi pers0nal,konflik padat, penulisan puisi, publikasikan puisi.

Model sinektik pada pembelajaran menulis puisi berkonteks multikultural sebagai produk pengembangan terbukti efektif untuk meningkatkan hasil pembelajamn menulis puisi berkonteks multikultural siswa SMA kelas X. Hal tersebut tampak pada hasil tes awal dan tes akhinf. Ketuntatasan akhir lebih besar dari tes awal. Tes awal yang tuntas 57,14\% dan tes akhir yang tuntas 100\%. Jadi ada peningkatan 42,86\% maka dapat disimpulkan bahwa pembelajaran menulis puisi berkonteks multikultural dapat ditingkatkan dengan menggunakan model sinektik.

\section{Daftar Pustaka}

Arends, Richardl. 1997. Classroom Instructional Management. New York: the Mc Graw-Hill Company

Aunurrahman, 2009. Belajar dan Pembelajaran . Bandung : Alfabeta.

Dahlan, M.D. 1990. Model-model Mengqiar. Bandung: Diponegoro.

Depdikbud. 1992. Jabaran Pelaksanaan UU No.2 T ahun I989. Semarang : PT. Wiclia Wiyata.

Djamarah, S.B. 1995. Strategi Belajar-Mengajar. Banjarmasin: Rineka Cipta.

Depdiknas. 2003. Pedoman Umum Pengembangan Silabus. Jakarta: Rancang Grafis Awanawan.

Effendi. S. 1982. B1'mbinganApresiasi Puisi. Jakarta : Pustaka Jaya.

Hamalik, Oemar. 2001. Kurikulum dan Pembelajaran. Jakarta : Bumi Aksara.

Joyce, Bruce. Marsha Well, dan Emily Cal Houn. 2009. Model of Teaching. Yogyakarta: Pustaka Pelajar.

Kasdi, S. dan Nur, M. 2000. Pengajaran Langsung. Surabaya: University Press.

Koesoema A, Doni. 2007. Pendidikan Karakter Strategi Mendidik Anak di Zaman Global. Jakarta : Grasindo. 
Lengkanawati, Nenden. 2005. Profesionalisme Guru Bahasa dalam Berkonteks Sertifikasi Guru dan Eksistensi LPTK. Pidato Pengukuhan Guru Besar

Tetap Universitas Pendidikan Indonesia, Bandung, 24 Nopember 2005.

Martaya, Widya. 1991. Seni Menuangkan Gagasan. Kanisius: Yogyakarta

Maslikhah, 2007. Qua Vadis Pendidikan Multikultural. Salatiga : STAIN Salatiga Press.

Nugroho, St. 2009. Multikulturalisme: Belajar Hidup Bersama dalam Perbedaan. Indeks. Jakarta; PT. Malta Printindo.

Nurhadi. 2003. Bagaimana Meningkatkan Kemampuan Membaca. Bandung: Sinar Baru Algensindo.

Nurgianto, Burhan. Belajar Bahasa Tak Bisa Abaikan Faktor Budaya.

www.com.kompas.com/kompas-cetak/03 10/ 1 4/jateng/424 1 14.htm.40k. diunduh 19 Juli 2009

Putra Winata, Udin S. 1995. Belajar dan Pembelajaran. Jakarta 1 Pusat Pembukuan Depdikbud.

Purwa, Bambang Kaswanti. 1997. Pokok-pokok Pengajaran Bahasa dan Kurikulum I994 Bahasa Indonesia. Jakarta : Departemen Pendidikan dan Kebudayaan.

Permana. 1999. Strategi Belajar-Mengajar. Jakarta: Depdikbud.

Pranoto. Naning. 2004. Creative Writing: 27 Jurus Seni Mengarang. Jakarta: Primamedia Pustaka.

Pradopo, Rachmat Djoko, 2005. Pengkajian Puisi. YogaIakarta : Gadjah Mada University Press.

Rozak. 2008. Model Diskusi Sastra di kelas 5 Sekolah Dasar Kola Cirebon. Tesis Magister pada PPS UPI Bandung: tidak diterbitkan.

Rusyana, Yus. 1986. Keterampilan Menulis. Jakarta : Universitas Terbuka.

Sagala, S. 2005. Konsep dan Makna Pembelajaran. Bandung: Alfabeta

Samsuri, 1985. Analisis Bahasa. Jakarta 1 Erlangga. I

Siswanto, Wahyudi. 2008. Pengantar Teori Saslra. Jakarta I Grasindo

Sindunata. 2000. Menggagas Paradigma Baru Pendidikan, Demokratisasi,

Otonomi, Civil Sociegv, Globalisasi. Yogyakartaz Kanisius.

Sudjana, N. dan Suwariyah, W. 1991. Model-model Mengajar CBSA. Bandung: Alfabeta.

Sudjiman, Panuti. 1986. Kamus Istilah Sastra. Jakarta : Gramedia

Sugiyon0.2008. Metode Penelitian Pendidikan. Bandung:Alfabeta.

Suharianto, S. I981. Pengantar Apresiasi Puisi. Syurakartaz Widya Duta.

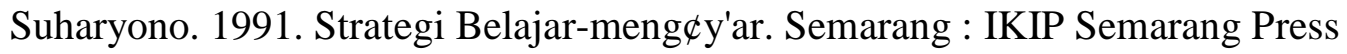

Sukmadinata, Nana Syaodih.2008 Metode Penelitian Pendidikan Bandung: PT. Remaja Rusdakarya 
Sundrijo, Dwi Ardhanariswari. 2007. Accomodative Multiculturalism: Altematif Pendekatan Terhadap Keragaman Budaya di Asia Tenggara. Global Jurnal Politik Intemasional. 166-186.

Soekamto, Toety, dan Udin Saripudin, Winata Putra. 1997. Teori Belajar dan ModelModel Pembelajaran. Jakarta: Depdikbud.

Syah, Muhibbin. 1995. Psikologi Pendidikan Suatu Pendekatan Baru. Bandung: PT Remaja Rosda Karya.

Tilaar, H.A.R. 2009. Multikulturalisme, Tantangan-tantangan Global Masa Depan dalam Transfbrmasi Pendidikan Nasional. Jakarta: Gramodia Widia Sarana : Indonesia.

Tilaar, H.A.R. 2007. Mengindonesia Etnisitas dan Identitas Bangsa Indonesia. Jakarta: Rineka Cipta.

Trianto, 2007. Model-model Pembelajaran Inovatif Berorientasi Konstruktivistilc Jakarta: Prestasi Pustaka.

Usman, M.U. 1989. Menjadi Guru Profesional. Bandung: PT. Remaja Rosdakarya.

Waluyo, Herman J. 2005. Apresiasi Puisi. Jakarta : Gramedia Pustaka Utama. 